\section{The Citrus Flavanone Naringin enhances Antioxidant Status in the Albino Rat Liver treated with Doxorubicin}

\section{Ganesh Chandra Jagetia and Vanessa Lalnuntluangi}

Department of Zoology, Mizoram University, Aizawl, Mizoram, India

\section{Abstract}

Doxorubicin is a used clinically to treat various neoplastic disorders and it acts by inducing oxidative stress in the neoplastic cells. However, the brunt of free radicals is also felt by the normal tissues leading to the development of second malignancies. Therefore any agent that is able to reduce doxorubicin-induced oxidative stress may be useful in reducing the toxicity of doxorubicin in normal cells during its clinical use. Liver is an important metabolic organ in the body and the aim of the present study was to evaluate the effect of naringin, a citrus bioflavanone on the doxorubicin-induced oxidative stress in rat liver. The rats were administered with $2 \mathrm{mg} / \mathrm{kg}$ body weight of naringin or $5 \mathrm{mg} / \mathrm{kg}$ body weight of doxorubicin alone or in combination with each other and the activities of glutathione-s-transferase, catalase and superoxide dismutase and glutathione and lipid peroxidation levels were determined at different post doxorubicin treatment times. Administration of doxorubicin alone caused a time dependent attrition in the activities of glutathiones-transferase, catalase and superoxide dismutase and glutathione concentration, accompanied by a significant increase in lipid peroxidation. Treatment of rats with naringin before doxorubicin administration significantly raised the glutathiones-transferase, catalase and superoxide dismutase activities and glutathione concentration followed by a reduced doxorubicin-induced lipid peroxidation. Our study demonstrates that naringin has been able to arrest the doxorubicin-induced oxidative stress by raising the antioxidant status and reducing lipid peroxidation.

Keywords: Doxorubicin; Naringin; Antioxidants; Lipid peroxidation; Rat; Liver
Corresponding author:

Dr. Ganesh Chandra Jagetia

\section{” gc.jagetia@gmail.com}

Department of Zoology, Mizoram University, Tanhril, Aizawl-796 004, Mizoram, India.

Tel: $0113892330724 / 2330227$

Citation: Jagetia GC, Lalnuntluangi V. The Citrus Flavanone Naringin enhances Antioxidant Status in the Albino Rat Liver treated with Doxorubicin. Biochem Mol Biol J. 2016, 2:2.

Received: May 02 2016; Accepted: May 28, 2016; Published: June 02, 2016

\section{Introduction}

The doxorubicin (DOX) was isolated from the pigment-producing Streptomyces peucetius in the 1960s [1]. It was introduced into clinical practice in the early 1970s, and since then it has become one of the most effective chemotherapy treatments for a broad range of malignant tumours such as lymphomas, myeloblastic leukemias, and various solid tumours including breast cancer, small cell lung cancer, ovarian cancer, childhood solid tumors and soft tissue sarcomas [2-4]. The doxorubicin is also frequently used to treat liver cancer as it has been regarded as one of the most effective chemotherapy to treat hepatocellular carcinoma [5].

The children and younger adults receiving anthracyclines for cancer cure are exposed to a lifetime risk of developing serious cardiomyopathy because cancer patients are not usually monitored beyond more than 5-7 years [6]. Chronic cardiotoxicity develops several years after treatment, whereas the irreversible acute cardiotoxicity develops early and the number of patients developing late cardiomyopathies may increase substantially in future $[7,8]$. Multiple mechanisms have been proposed to explain anthracycline-induced cardiotoxicity, however it is widely accepted that the formation of oxygen free radicals and participation of iron ions are the major causes of cardiotoxicity [7-9]. Doxorubicin has been known to generate highly reactive free radicals in the mitochondria of cells and presence of iron further aggravates the problem [10]. The DOX produces quinone-hydroquinone containing anthracyclines, which are redox active and therefore undergo both one-electron and two-electron reductions by a wide variety of chemical and enzymatic reducing agents $[2,11,12]$. The one-electron reduction of DOX casues the formation of semiquinone free radicals or other reactive species that could exert antitumor action either by alkylating DNA, by causing DNA strand scission, or by inducing lipid peroxidation [13]. 
The endogenous antioxidants and enzymes are known to play a crucial role in inactivating these free radicals [14]. The heart is particularly vulnerable to damage induced by free radicals because protective enzymes such as superoxide dismutase and catalase are present at a lower level than in other tissues of the body $[15,16]$. The use of antioxidants to prevent DOX-induced toxicity may be a prudent strategy. In fact antioxidants and cardioprotective agents have been combined to abate DOX-induced cardiac toxicity without compromising with its antitumor activity [1719]. Dexazoxane, a bisdioxopiperazine compound is a clinically approved to alleviate doxorubicin cardiotoxicity in cancer patients [20]. However, it is known to induce especially hematological and hepatotoxicities, which encourages further investigations of new cardioprotectants with lower toxicities. Other agents such as venoruton (a standardized mixture of flavonoids), propolis (bee glue), and many other natural antioxidants have been clinically evaluated for their cardioprotective efficacy, but with limited success [21]. Recently, extract of Aegle marmelos has been reported to reduce DOX-induced cardiotoxicity in preclinical investigation without compromising to DOX's anticancer activity [19].

Naringin is a predominant flavanone, found in grapefruit Citrus paradisi and it is also present in other plants including Citrus sinensis, Citrus unshiu, Citrus nobilis, Citrus tachibana, Citrus junos, Artemisia selengensis, Artemisia stolonifera, roots of Cudrania cochinchinensis, aerial parts of Thymusherba barona, fruits of Pon cirus and related citrus species [22]. Naringin has been reported to scavenge free radicals and possess metal chelating, and antioxidant properties [23-27]. It has been found to protect against Parkinson's disease in preclinical studies [28]. Naringin has been found to protect against mutagenesis and lipid peroxidation [29-32]. Earlier studies from this laboratory have indicated that naringin reduced the radiation-induced micronuclei formation and chromosomal aberrations in mice and bleomycininduced DNA strand breaks in cultured V79 cells $[25,33,34]$. It has also been found to protect against the doxorubicin-induced caridiotoxicity without alleviating its antitumor activity in mouse [18]. However, the effect of doxorubicin on the antioxidant profile of albino rats and its modulation by naringin has not been investigated. Therefore the present study was designed to investigate the effect of naringin on the antioxidant status of rats treated with doxorubicin.

\section{Materials and Methods}

\section{Chemicals}

Doxorubicin (Biochem Pharmaceutical Industries, Mumbai, India) was purchased from a local supplier, whereas naringin was supplied by Acros Organics Ltd, Geel, Belgium. Phenozine methosulphate, nitroblue tetrazolium, NADH, thiobarbituric acid, trichloroacetic acid, 5,5-dithio2-nitrobenzoic acid (DTNB), GSH, and 1-chloro,2,4-dinitrobenzene (CDNB) were obtained from Sigma Aldrich India, Kolkata. Potassium dihydrogen phosphate, disodium hydrogen phosphate, hydrogen peroxide, dipotassium hydrogen phosphate and other routine chemicals were procured from Merck India Ltd., Mumbai, India.

\section{Animal handling}

The animal care and handling were done according to the guidelines issued by the World Health Organization, Geneva, Switzerland and the INSA (Indian National Science Academy, New Delhi, India). Six to eight weeks old albino rats weighing 45-60 g were procured locally. The animals were housed in polypropylene cages in the controlled conditions of temperature and light $(12 \mathrm{~h}$ of light and dark each). The study was approved by Institutional Animal Ethics Committee (IAEC) of Mizoram University, Aizawl, India.

\section{Preparation of drugs and mode of administration}

Naringin (NIN) or doxorubicin hydrochloride (DOX) was freshly prepared in sterile double distilled water (DDW), immediately before use. The animals were injected with either $2 \mathrm{mg} / \mathrm{g}$ body weight (b. wt.) NIN or $5 \mathrm{mg} / \mathrm{kg}$ b. wt. DOX intraperitoneally.

\section{Experimental}

The animals were divided into the following groups to study the antioxidant action of naringin:

- Control: The animals were administered with distilled water intraperitoneally.

- Naringin: Animals were administered with $2 \mathrm{mg} / \mathrm{kg} \mathrm{b}$. wt. naringin intraperitoneally [33].

- Doxorubicin: Animals of this group were administered with $5 \mathrm{mg} / \mathrm{kg} \mathrm{b}$. wt. of doxorubicin intraperitoneally.

- Naringin + Doxorubicin: This group of animals was administered with $2 \mathrm{mg} / \mathrm{kg}$ b. wt. naringin intraperitoneally once daily consecutively for three days. One hour after the last administration of naringin, $5 \mathrm{mg} / \mathrm{kg}$ b. wt. of doxorubicin was administered intraperitoneally [18]. The animals from all groups were killed by cervical dislocation at $1 / 2,1$ and 2 hours post DOX administration. The animals were dissected and perfused with ice cold saline transcardially.

\section{Preparation of homogenate}

The liver was excised, blot dried, weighed and $10 \%$ homogenate was prepared in phosphate buffered saline for the estimation of glutathione, glutathione-s-transferase, catalase, superoxide dismutase, and Lipid peroxidation.

\section{Total proteins}

The protein contents were determined using the modified method of Lowry.

\section{Glutathione}

The glutathione concentration was measured by the method of Moron et al. [35]. Briefly, proteins were precipitated by $25 \%$ TCA, and centrifuged. The supernatant was transferred into another tube, mixed with $0.2 \mathrm{M}$ sodium phosphate buffer $(\mathrm{pH}$ 8.0) and $0.06 \mathrm{mM}$ DTNB, and incubated for 10 minutes at room temperature. The absorbance of the sample/s was read against the blank at $412 \mathrm{~nm}$ in a UV-VIS double beam spectrophotometer (Shimadzu Corporation, Tokyo, Japan) and the GSH concentration has been calculated from the standard curve.

\section{Glutathione-S-transferase}

Glutathione-S-transferase (GST) was determined by the method of Habig et al. [36]. Briefly, the liver homogenate was mixed with $0.1 \mathrm{M}$ potassium phosphate buffer, $1 \mathrm{mM}$ EDTA, glutathione 
reductase, $10 \mathrm{mM} \mathrm{GSH}, 12 \mathrm{mM}$ tert-butyl-hydroperoxide and incubated for $10 \mathrm{~min}$ at $37^{\circ} \mathrm{C}$. The absorbance was read against the blank at $340 \mathrm{~nm}$ using a double beam UV-VIS spectrophotometer.

\section{Catalase}

The catalytic reduction of hydrogen peroxide was used as a measure of catalase activity as described earlier [37]. Briefly, the sample was mixed with hydrogen peroxide and incubated at $37^{\circ} \mathrm{C}$. The decomposition of hydrogen peroxide was monitored every 30 seconds by recording the absorbance against the blank at $240 \mathrm{~nm}$ using a UV-VIS double beam spectrophotometer.

\section{Superoxide dismutase}

Total SOD activity, was determined by the pyrogallol autooxidation method [38]. Briefly, the sample was added to $62.5 \mathrm{mM}$ tris-cacodylic acid buffer, containing $1 \mathrm{mM}$ diethylenetriaminepentaacetic acid (DETAPA), followed by the addition of $4 \mathrm{mM}$ pyrogallol. The autooxidation of pyrogallol was monitored against the blank at $420 \mathrm{~nm}$ using a UV-VIS double beam spectrophotometer.

\section{Lipid peroxidation (LOO)}

Lipid peroxidation was estimated according to the standard protocol [39]. Briefly, the samples were incubated with a mixture of trichloroacetic acid (15\%), thiobarbituric acid $(0.375 \%)$, and butylated hydroxytoluene $(0.01 \%)$ in $0.25 \mathrm{~N} \mathrm{HCl}$ at $95^{\circ} \mathrm{C}$ for $25 \mathrm{~min}$. The reaction mixture was allowed to cool to room temperature and was centrifuged at $8,000 \mathrm{~g}$. The supernatant was collected and the absorbance was recorded against the blank using a UV-VIS double beam spectrophotometer. The lipid peroxidation has been determined against a standard curve prepared with tetraethoxypropane. For all biochemical estimations duplicate samples were used from each animal for various estimations listed above and a minimum of five animals were used for each concurrent group and a total of forty animals were utilized for this experiment.

\section{Statistical Analysis}

The significance between the treatments was determined using the Student's ' $\mathrm{t}$ ' test. A $\mathrm{p}$ value of $<0.05$ was considered statistically significant. The Solo 4 statistical package (BMDP Statistical Software Inc, Los Angeles, CA, USA) was used for statistical analyses.

\section{Results}

The results are shown as mean \pm standard error of the mean in Table 1 and Figure 1-5.

\section{Glutathione}

The spontaneous glutathione concentration in the non-drug treated control albino rats was $26 \pm 1.7 \mathrm{nmol} / \mathrm{mg}$ protein. Naringin treatment did not alter the GSH concentration significantly as compared to control (Table 1). Doxorubicin treatment resulted in a significant decline in the GSH concentration as early as 0.5 $\mathrm{h}$ post treatments, which were approximately 2 folds lower than the spontaneous GSH concentration (Table 1 and Figure 1). The GSH concentration continued to decline with assay time and almost 2.5 and 5 fold depletion was observed at 1 and $2 \mathrm{~h}$ postDOX treatment in the liver of rats receiving DOX alone (Table 1 and Figure 1). The pattern of decline in the GSH concentration in naringin+DOX treated group was almost similar to that of DOX treatment alone (Figure 1). However, naringin treatment prior to DOX administration resulted in a significant elevation in the GSH concentration at all post-DOX-treatment times when compared to DOX-treatment alone (Table 1 and Figure 1).

\section{Glutathione-S-transferase}

The glutathione-s-transferase activity of non-drug treated control animals was $0.75 \pm 0.01 \mathrm{nmol} / \mathrm{mg}$ protein and naringin administration alone did not alter the glutathione-s-transferase

Table $1 \mathrm{Effect}$ of $2 \mathrm{mg} / \mathrm{kg}$ body weight of naringin on the various antioxidants at different post-treatment times in the liver of albino rats treated with $5 \mathrm{mg} / \mathrm{kg}$ body weight doxorubicin. $\mathrm{p} \leq 0.05$; *Significant as compared to control. \#Significant as compared to doxorubicin alone treatment and no symbols = non-significant; $\mathrm{N}=3$.

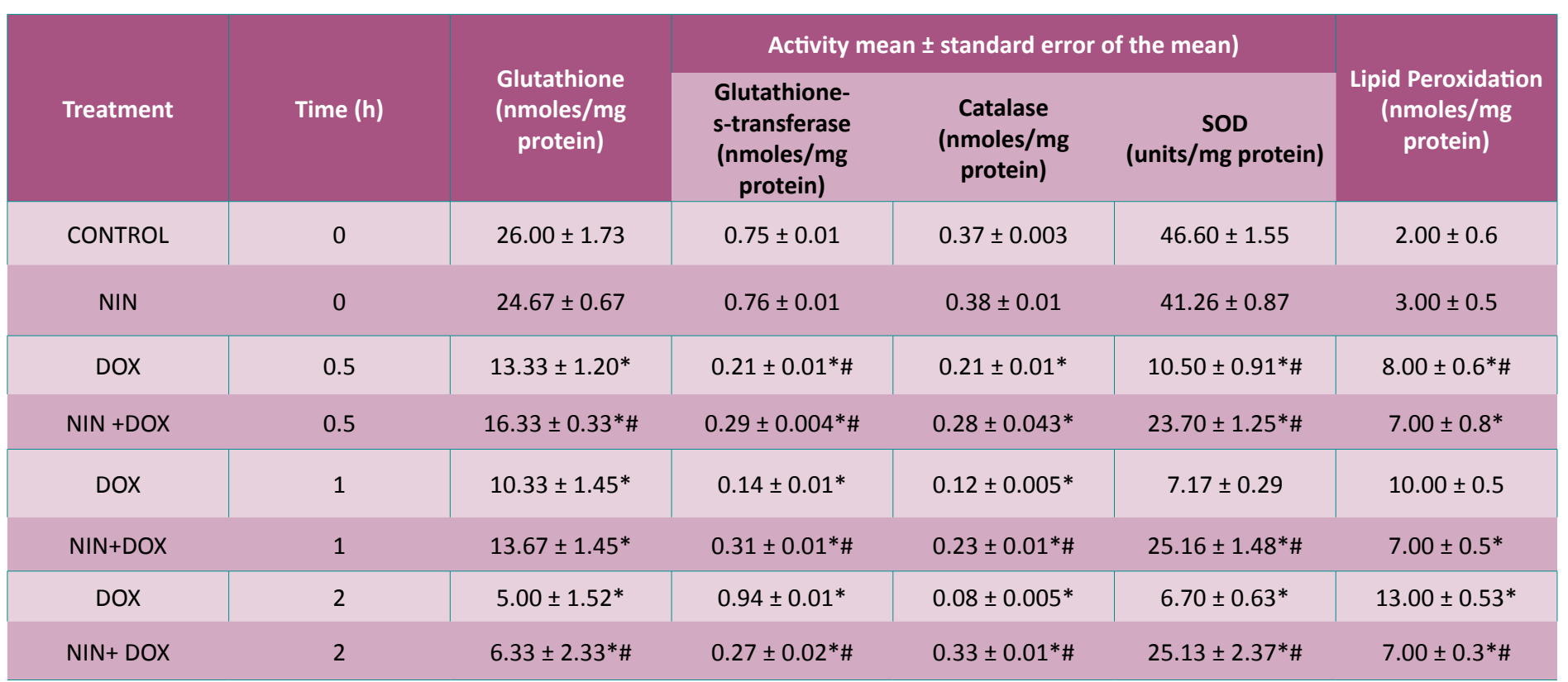




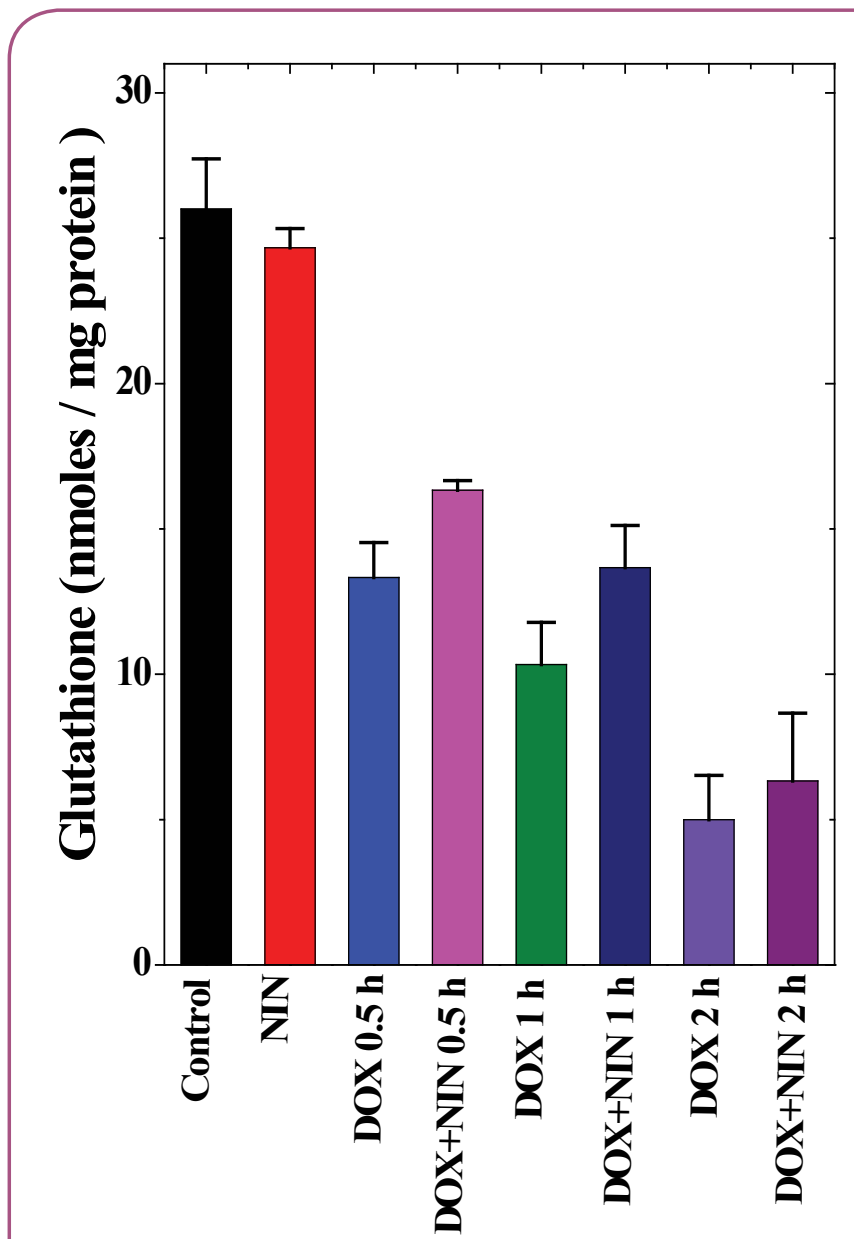

Figure 1 Alteration in the doxorubicin-induced glutathione concentration at different post DOX treatment times in the liver of rats treated with naringin.

activity significantly as compared to control (Table 1). Doxorubicin treatment caused a significant decline in the GST activity, which was 3 fold lower than the control activity at $0.5 \mathrm{~h}$ post-DOXtreatment (Table 1 and Figure 2). Increase in assay time resulted in a further decline in the GST activity and it reached a nadir at $2 \mathrm{~h}$ post-DOX-treatment, where it was almost 8 fold lower than the non-drug treated control. Naringin treatment significantly raised the GST activity at all post-DOX-treatment times in the naringin+DOX group when compared to DOX treatment alone. However, a maximum increase of 2.8 fold was observed at $2 \mathrm{~h}$ post-DOX-treatment (Table 1 and Figure 2).

\section{Catalase}

The spontaneous catalase activity in the control rat liver was $0.366 \pm 0.003 / \mathrm{mg}$ protein and naringin treatment did not alter the spontaneous catalase activity significantly (Table 1 and Figure 3 ). The administration of DOX to rats resulted in a significant decline in the catalase activity at all post-DOX-treatment assay times as compared to control (Figure 3). The DOX treatment caused a 3 and 4.34 fold reduction in the catalase activity at 1 and $2 \mathrm{~h}$ postDOX-treatment when compared to spontaneous catalase activity (Table 1). Naringin treatment before doxorubicin administration elevated the catalase activity significantly, which was $1.3,1.9$ and 4.9 folds higher at 0.5, 1 and $2 \mathrm{~h}$ post-DOX-treatment when compared to DOX treatment alone (Table 1 and Figure 3).

\section{Superoxide dismutase}

The spontaneous superoxide dismutase activity in the rat liver was $46.6 \pm 1.55 \mathrm{nmol} / \mathrm{mg}$ protein and naringin treatment did alter the spontaneous SOD activity significantly (Table 1 and Figure 4). The doxorubicin treatment alone significantly reduced the SOD activity at all post-DOX-treatment assay times as compared to control (Table 1). This alleviation in SOD activity was $4,6.5$ and 7 folds lower than the spontaneous activity at $0.5,1$ and $2 \mathrm{~h}$ post-DOX-treatment, respectively in comparison to the spontaneous SOD activity. The naringin treatment before DOX administration did not alter the pattern of decline in the SOD activity in naringin+DOX group, except that the SOD activity was significantly enhanced (Figure 4). The SOD activity was 2 fold greater at $0.5 \mathrm{~h}$, whereas this elevation was approximately 3.5 fold at 1 and $2 \mathrm{~h}$ post-DOX-treatment, respectively (Table 1).

\section{Lipid peroxidation}

The results of the present study show that the rate of lipid peroxidation in the liver of control albino rat was $0.2 \pm 0.06 \mathrm{nM} / \mathrm{mg}$ protein. Naringin administration to rats alone had no significant effect on the spontaneous lipid peroxidation (Table 1). Treatment of rats with doxorubicin increased the lipid peroxidation $(8.3 \pm$

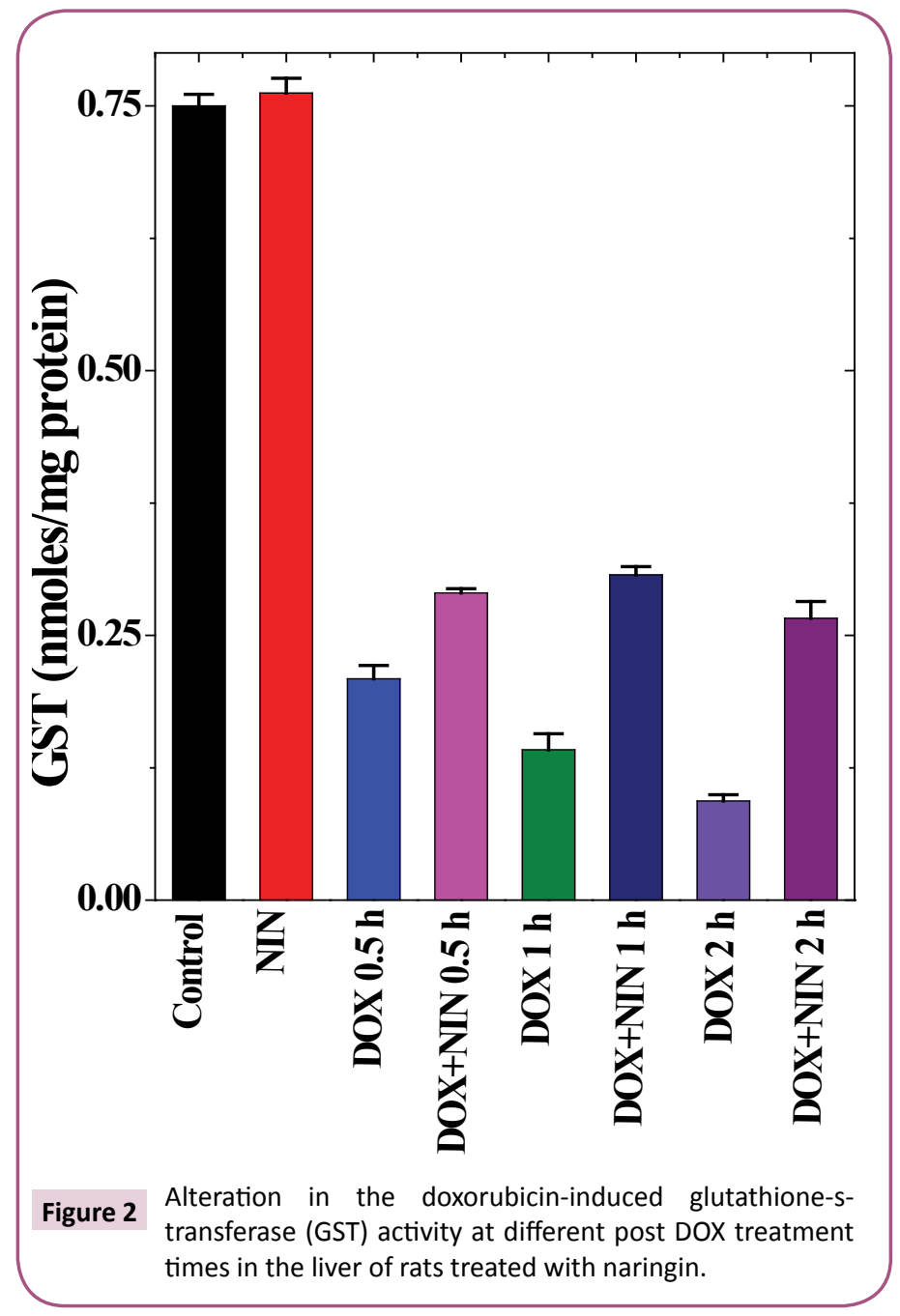




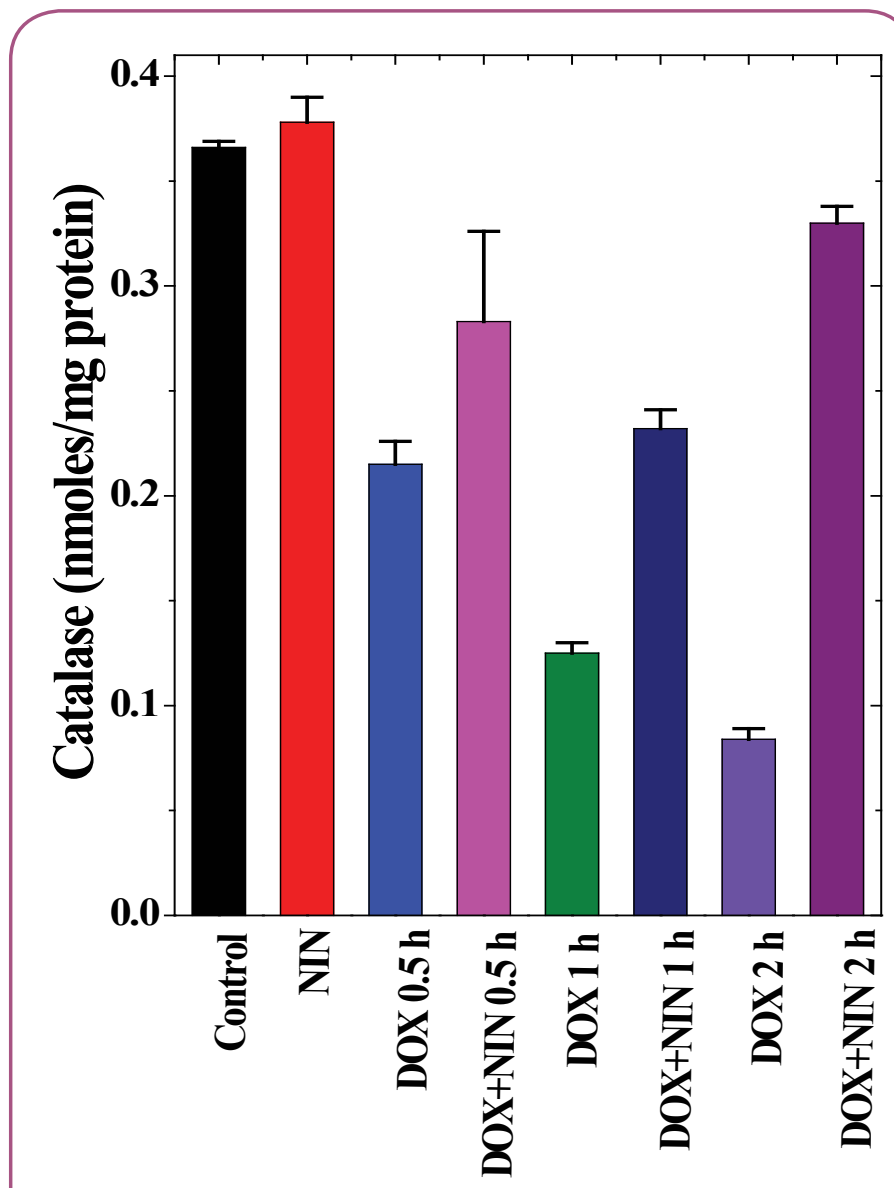

Figure 3 Alteration in the doxorubicin-induced catalase activity at different post DOX treatment times in the liver of rats treated with naringin.

0.6) significantly when compared to spontaneous levels $(0.2 \pm$ $0.06)$, which continued to rise with assay time until a maximum lipid peroxidation of $13 \pm 0.5 \mathrm{nM}$ was recorded at $2 \mathrm{~h}$ post-DOXtreatment (Table 1 and Figure 5). Naringin treatment before DOX administration significantly reduced the rate of lipid peroxidation $(8.73 \pm 1.24)$, when compared to DOX treatment alone (Figure 5), which was approximately half of the DOX-treatment alone. Despite this decline, the lipid peroxidation was greater than the spontaneous (Figure 5 and Table 1).

\section{Discussion}

The use of oxygen by the organism comes with the cost of free radical production. The free radicals are essential for several biological processes. They act as signaling molecules and also they are utilized to combat infection [40]. However, excess production of free radicals and failure to neutralize free radicals by endogenous antioxidants has been linked to several disease states including aging, heart and cardiovascular diseases, gastrointestinal tract disorders, diabetes, cataractogenesis, degenerative retinal damage, autoimmune nephrotic syndromes, heavy metal toxicity, Parkinson's disease, Alzheimer's disease, bronchopulmonary dysphasia, ischemia reflow states and cancer $[41,42]$. Doxorubicin acts on the neoplastic cells by inducing free radicals. These free radicals also produce negative impact on the normal cells and the cardiotoxicity produced by the anthracylines is believed to be due to their ability to produce free radicals. Therefore, the present study was undertaken to evaluate the effect of naringin on the negative effect of doxorubicin on various endogenous antioxidants in rat liver.

Glutathione or $y$-glutamylcysteinylglycine (GSH) is synthesized by cells to defend themselves against the oxidative stress induced by excess free radicals so as to keep the cell healthy [43-45]. Its decline is associated with increased oxidative stress and alteration in the structural and functional integrity of cells $[44,45]$. The decrease in the GSH will lead to toxic effects in tissues of any organism. Treatment of rats with doxorubicin reduced the concentration of GSH in the liver and this attrition in glutathione may have led to increased oxidative stress in the rat liver. Our results are in conformation to others where DOX has been found to reduce GSH level in mice and rat liver and heart earlier $[18,19,46]$. Naringin administration abated the doxorubicin induced GSH decline. Earlier naringin has been reported to elevate the GSH concentration in the heart and liver of doxorubicin treated mice and rats $[18,47,48]$. Similarly, extract of Agele marmalos has been reported to elevate myocardial glutathione concentration in mice [19]. Glutamine an amino acid has been reported to protect against the DOX-induced depletion in GSH in rats [46].

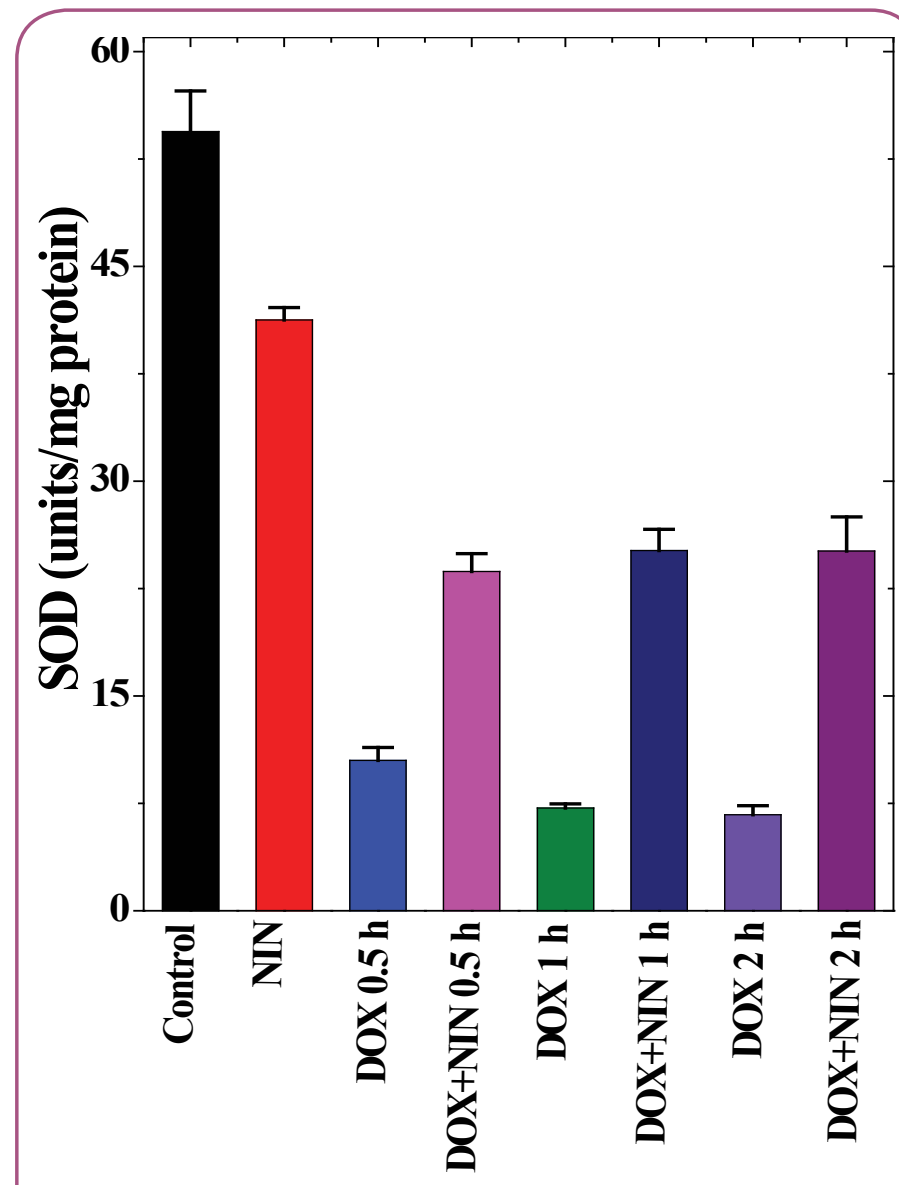

Figure 4 Alteration in the doxorubicin-induced superoxide dismutase (SOD) activity at different post DOX treatment times in the liver of rats treated with naringin. 


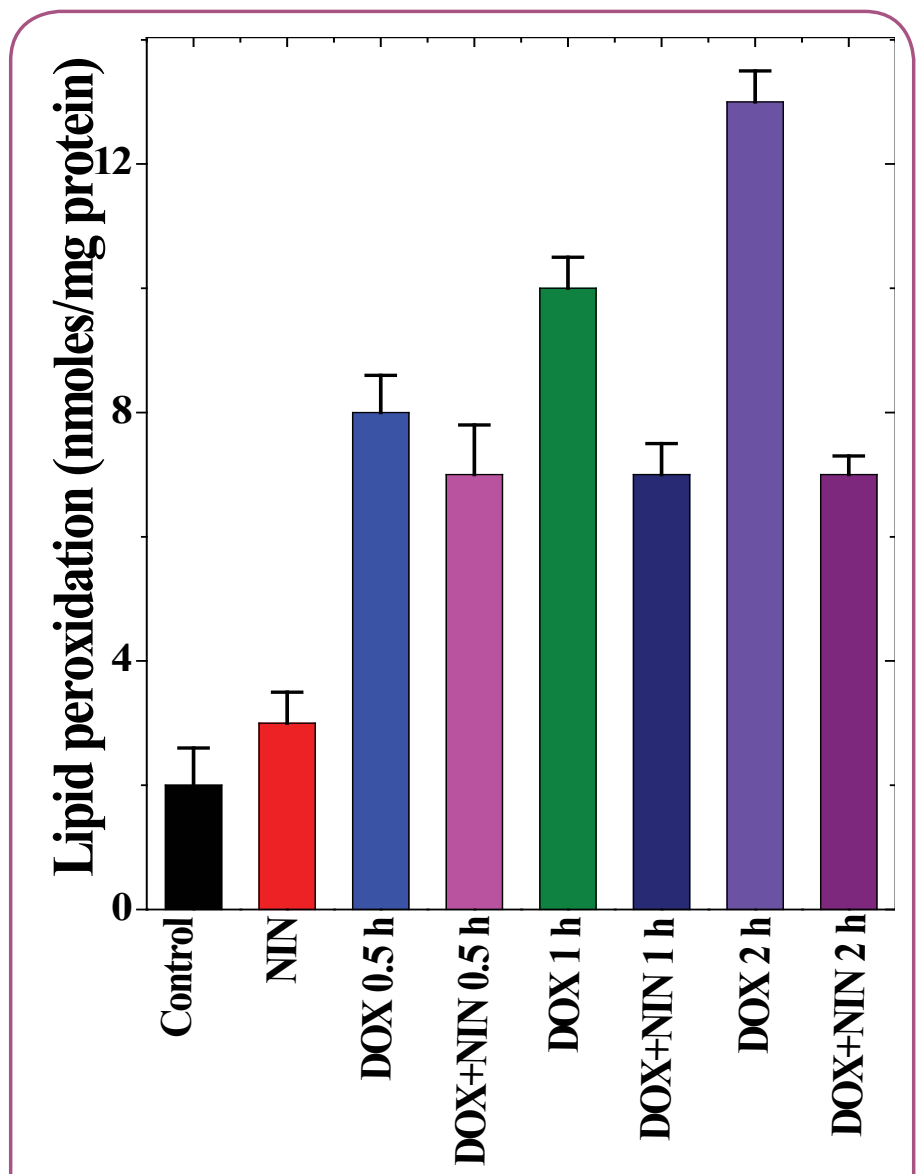

Figure 5 Alteration in the doxorubicin-induced lipid peroxidation at different post DOX treatment times in the liver of rats treated with naringin.

The reduction of GST in the DOX treated group may be the major cause of DOX-induced oxidative stress and cell death as they play major role in detoxification and protection of DNA from various toxicants [49]. The GSTs are synthesized by all organisms, which conjugate with GSH to a variety of endogenic and exogenic electrophilic substances, and regulate cell demise and proliferation [50]. The overexpression of GST is related to resistance against chemotherapy of cancer [51]. Doxorubicin treatment has led to a significant decline in the GST activity in the present study, which may be responsible for its cytotoxic effects. The activity of GST after DOX treatment has been studied to a lesser extent however it has been reported to reduce GST activity in the heart and liver of mice earlier [19]. It is found to be reduced in hypertensive rats [52]. The DOX-induced cardiomyopathy may be due to its ability to reduce GST. Naringin administration resulted in a significant elevation in the GST activity in the present study. Earlier naringin has been found to diminish the DOX-induced decline in the GST activity in mouse liver and heart [18].

Oxygen is an essential evil it is indispensible for energy production in aerobic life however due to its high reactivity it generates reactive oxygen species which are deleterious to the organisms. The organisms have evolved counter measures to spare themselves from the deleterious effects of oxygen. During respiration superoxide radical (reactive form of oxygen) is generated and it is converted into a less harmful product, the hydrogen peroxide by the enzyme superoxide dismutase which is present inside the cell as well in the extracellular matrix [5355]. Oxidative stress has been indicated as an essential factor in the induction of cardiotoxicity, nephrotoxicity and heptotoxicity in cancer patients receiving chemotherapeutic drugs including doxorubicin. The doxorubicin interacts with eNOS and enhances the production of superoxide radical, which induces toxic effects [56]. This may cause reduced SOD activity as observed in the present study. The reduction in SOD activity by DOX has been reported in mice earlier $[18,19]$. The naringin treatment elevated the SOD activity significantly in the rat liver reducing its toxicity. Earlier naringin has been reported to increase the SOD activity in the heart and liver of mice and rats treated with DOX $[18,47,48]$. It has been found to increase SOD activity in the bleomycin treated rat lung [57]. The extract of Aegle marmelos has also been found to protect against the DOX-induced reduction in the SOD activity [19].

The catalase enzyme is a tetrameric protein and it catalyzes the breakdown of hydrogen peroxide into water and molecular oxygen [58] reducing the toxic effects of hydrogen peroxide. Doxorubicin treatment reduced catalase activity in the rats, which is in conformation to earlier studies where DOX has been reported to alleviated catalase activity in the heart and liver of mice $[18,19]$. Similarly, rat heart has shown a reduced catalase activity after DOX treatment [48]. Naringin has been reported to enhance the catalase activity in the liver in the present study. An identical increase in the catalase activity has been reported earlier in rat heart and mice liver and heart treated with naringin before doxorubicin administration $[18,47,48]$. Likewise, Aegle mamrmelos extract has been found to protect against doxorubicin-induced depletion in the catalase activity of mice heart [19].

Cell membrane lipids are primary target of free radicals generated during oxygen utilization and these free radicals interacts with membrane lipids to produce peroxides of lipids [59]. Therefore, lipid peroxidation has been regarded as an indirect measure of oxidative stress. Superoxide and hydrogen peroxide are important byproducts in usual cellular energy metabolism. As such they are not highly toxic but uncompartmentalized excess iron might initiate the formation of $\mathrm{OH}$ radical, which may initiate lipid peroxidation via Fenton/Haber-Weiss reaction [13]. The increased lipid peroxidation by doxorubicin may have involved similar mechanism in the present study. This is in good agreement with earlier studies, where DOX has been reported to increase lipid peroxidation in mice and rat heart and liver $[18,19,46,47,48,60]$. Naringin has been reported to protect against the DOX-induced lipid peroxidation in mouse liver and heart [18]. Naringin also reduced radiation or iron induced lipid peroxidation in vivo and in vitro $[27,32,61]$. It has been reported to alleviate DOX induced lipid peroxidation in mice and rat liver and heart $[47,48]$. Likewise, naringin has been found to reduce bleomycin-induced lipid peroxidation in rat lung [57]. The L-glutamine has been also reported to protect against the DOX-induced lipid peroxidation in rat heart [46].

The exact mechanism of action of naringin to arrest the doxorubicin-induced decline in antioxidants is not known. The 
free radical scavenging activity of naringin may have inhibited or neutralized the free radicals generated by doxorubicin and protected the attrition of GSH, GST, catalase and SOD in the present study. Naringin has been reported to scavenge free radicals earlier [25]. Doxorubicin also generates greater amount of free radicals in the presence of iron, and the presence of naringin may have chelated iron thereby reducing the free availability of iron to doxorubicin. This would have reduced free radical production capacity of DOX. Naringin has been reported to chelate iron earlier [27]. The ability of naringin to arrest the DOX-induced attrition in GSH, GST, catalase and SOD may have subsequently reduced the lipid peroxidation by reducing the oxidation of cellular lipids. At molecular level, the DOX has been reported to increase the activation of NF-KB and COX-II in cardiomyocytes $[12,62,63]$ and inhibition of NF-KB and COX-II by naringin may have suppressed the inflammation and reduced the DOX-induced hepatotoxicity in the present study. Naringin has been reported to suppress the transcription of NF-KB and COX-II in vitro [64]. Nrf2s nuclear transcription factors are essential in expression of antioxidant response element genes [65] and the down regulation of $\mathrm{Nrf} 2$ by doxorubicin may have reduced the antioxidants and increased the lipid peroxidation in the present study. The presence of naringin may have inhibited the DOXinduced downmodulation of Nrf2 transcription factor resulting in the increased antioxidant status and reduced lipid peroxidation in the rat liver. Naringin has been reported to activate Nrf2 signalling pathway [66].

The naringin pre-treatment has been able to elevate the GSH concentration and activities of GST, catalase and superoxide dismutase. This was accompanied by a significant decline in the doxorubicin-induced lipid peroxidation in the rat liver. This may be due to the free radical scavenging activity of naringin and also its ability to chelate iron, which is implicated in the enhancement of doxorubicin-induced free radicals. Naringin may have also inhibited the activation of DOX-induced NF-KB, and COX-II and increased the transcriptional activation of $\mathrm{Nrf2}$ in rat liver thereby increasing the antioxidant status in the rat liver.

\section{Acknowledgement}

This work was carried out under a Grant from University Grants Commission and Department of Biotechnology, Government of India, New Delhi to Prof. GCJ. 


\section{References}

1 Arcamone F, Cassinelli G, Fantini G, Grein A, Orezzi P, et al. (1969) Adriamycin, 14-hydroxydaunomycin, a new antitumor antibiotic from S. peucetius var. caesius. Biotechnol Bioeng 9: 1101-1110.

2 Minotti G, Menna P, Salvatorelli E, Cairo G, Gianni L (2004) Anthracyclines: molecular advances and pharmacologic developments in antitumor activity and cardiotoxicity. Pharmacol Rev 56: 185-229.

3 Quiles JL, Ochoa JJ, Huertas JR, Lopes-Frias M, Mataix J (2006) Olive oil and mitochondrial oxidative stress: studies on adriamycin toxicity, physical exercise and ageing. CABI Publishing, UK.

4 Volkova M, Russell R (2011) Anthracycline cardiotoxicity: prevalence, pathogenesis and treatment. Curr Cardiol Rev 7: 214-220.

5 Tam K (2013) The Roles of doxorubicin in hepatocellular carcinoma. ADMET \& DMPK 1: 29-44.

6 Lipshultz SE, Lipsitz SR, Kutok JL, Miller TL, Colan SD, et al. (2013) Impact of hemochromatosis gene mutations on cardiac status in doxorubicin-treated survivors of childhood high-risk leukemia. Cancer 119: 3555-3562.

7 Tacar O, Sriamornsak P, Dass CR (2013) Doxorubicin: an update on anticancer molecular action, toxicity and novel drug delivery systems. J Pharm Pharmacol 65: 157-170.

8 Carvalho FS, Burgeiro A, Garcia R, Moreno AJ, Carvalho RA, et al. (2014) Doxorubicin-induced cardiotoxicity: from bioenergetic failure and cell death to cardiomyopathy. Med Res Rev 34: 106-135.

9 Myers C (1998) The role of iron in doxorubicin-induced cardiomyopathy. Semin Oncol 25: 10-14.

10 Ichikawa Y, Ghanefar M, Wu R, Khechaduri A, Prasad SVN, et al. (2014) Cardiotoxicity of doxorubicin is mediated through mitochondrial iron accumulation. J Clin Invest 124: 617-630.

11 Mordente A, Meucci E, Silvestrini A, Martorana GE, Giardina B (2009) New developments in anthracycline-induced cardiotoxicity. Curr Med Chem 16: 1656-1672.

12 Octavia Y, Tocchetti CG, Gabrielson KL, Janssens S, Crijns HJ, et al. (2012) Doxorubicin-induced cardiomyopathy: from molecular mechanisms to therapeutic strategies. J Mol Cell Cardiol 52: 1213-1225.

13 Halliwell B, Gutteridge JMC (1989) Free radicals in biology and medicine. (2ndedn) Oxford University Press, New York, US.

14 Kaul N, Siveski-lliskovic N, Hill M, Slezak J, Singal PK (1993) Free radicals and the heart. J Pharmacol Toxicol Methods 30: 55-67.

15 Takács IE, Matkovics B, Varga SI, Homolay P, Fehér G, et al. (1992) Study of the myocardial antioxidant defense in various species. Pharmacol Res 25: 177-178.

16 Childs AC, Phaneuf SL, Dirks AJ, Phillips T, Leeuwenburgh C (2002) Doxorubicin treatment in vivo causes cytochrome $C$ release and cardiomyocyte apoptosis, as well as increased mitochondrial efficiency, superoxide dismutase activity, and Bcl-2: Bax ratio. Cancer Res 62: 4592-4598.

17 Singal PK, Kirshenbaum LA (1990) A relative deficit in antioxidant reserve may contribute in cardiac failure. Can J Cardiol 6: 47-49.

18 Jagetia GC, Reddy TK (2014) The grape fruit flavonone naringin protects mice against doxorubicin-induced cardiotoxicity. J Mol Biochem 3: 34-49.

19 Jagetia GC, Venkatesh P (2015) An Indigenous plant Bael (Aegle marmelos (L.) Correa) extract protects against the doxorubicininduced cardiotoxicity in mice. Biochem Physiol 4: 163.
20 Weiss RB (1992) The anthracyclines: will we ever find a better doxorubicin? Semin Oncol 19: 670-686.

21 Hrdina R, Geršl V, Klimtová I, Šimùnek T, Macháèková J, et al. (2000) Anthracycline-induced cardiotoxicity. Acta medica 43: 75-82.

22 Swiader K, Zarawska E (1996) Flavonoids of rare Artemesia species and their antifungal properties. Fitotherapia 67: 77-78.

23 Russo A, Acquaviva R, Campisi A, Sorrenti V, Di Giacoma C, et al. (2000) Bioflavonoids as antiradicals, antioxidants and DNA cleavage protectors. Cell Biol Toxicol 16: 91-98.

24 Jeon SM, Bok SH, Jang MK, Kim YH, Nam KT, et al. (2002) Comparison of antioxidant effects of naringin and probucol in cholesterol-fed rabbits. Clin Chim Acta 317: 181-190.

25 Jagetia GC, Venkatesha VA, Reddy TK (2003) Naringin, a citrus flavonone, protects against radiation-induced chromosome damage in mouse bone marrow. Mutagenesis 18: 337-343.

26 Gorinstein S, Leontowicz H, Leontowicz M, Krzeminski R, Gralak M, et al. (2007 Effect of hesperidin and naringin on the plasma lipid profile and plasma antioxidant activity in rats fed a cholesterol-containing diet. J Sci Food Agric 87: 1257-1262.

27 Jagetia GC, Reddy TK (2011) Alleviation of iron induced oxidative stress by the grape fruit flavanone naringin in vitro. Chem Biol Interact 190: 121-128.

28 Kim DH, Jeong KH, Jung UJ, Kim SR (2016) Naringin treatment induces neuroprotective effects in a mouse model of Parkinson's disease in vivo, but not enough to restore the lesioned dopaminergic system. J Nutr Biochem 28: 140-146.

29 Chen YT, Zheng RL, Jia ZJ, Ju Y (1990) Flavonoids as superoxide scavengers and antioxidants. Free Rad Biol Med 9: 19-21.

30 Calomme M, Pieters L, Vlietinck A, Vanden BD (1996) Inhibition of bacterial mutagenesis by citrus flavonoids. Planta Med 62: 222-226.

31 Bear WL, Teel RW (2000) Effects of citrus flavonoids on the mutagenicity of heterocyclic amines and on cytochrome P450 1A2 activity. Anticancer Res 20: 3609-3614.

32 Jagetia GC, Reddy TK (2005) Modulation of radiation induced alteration in the antioxidant status of mice by naringin. Life Sci 77 : 780-794.

33 Jagetia GC, Reddy TK (2002) The grapefruit flavanone naringin protects against the radiation-induced genomic instability in the mice bone marrow: a micronucleus study. Mutat Res 26: 37-48.

34 Jagetia A, Jagetia GC, Jha S (2007) Naringin, a grape fruit flavanone, protects V79 cells against the bleomycin-induced genotoxicity and decline in the survival. Journal of Applied Toxicology 27: 122-132.

35 Moron MS, Depierre JW, Mannervik B (1979) Levels of glutathione, glutathione reductase and glutathione S-transferase activities in rat lung and liver. Biochim Biophy Acta 582: 67-78.

36 Habig WH, Pabst MJ, JakobyWB (1974) Glutathione S-transferases. The first enzymatic step in mercapturic acid formation, J Biol Chem 249: 7130-7139.

37 Abei H (1984) Catalase in vitro. Methods Enzymol 105: 121-126.

38 Marklund S, Marklund G (1974) Involvement of the superoxide anion radical in the autooxidation of pyrogallol and a convenient assay for superoxide dismutase. Eur J Biochem 47: 469-474. 
39 Gelvan D, Saltman P (1990) Different cellular targets of Cu- and Fecatalyzed oxidation observed using a Cu-compatible thiobarbiturate acid assay. Biochim Biophys Acta 1035: 353-360.

40 McCord JM (2000) The evolution of free radicals and oxidative stress. Am J Med 108: 652-659.

41 Dröge W (2002) Free radicals in the physiological control of cell function. Physiol Rev 82: 47-95.

42 Pham-Huy LA, He H, Pham-Huy C (2008) Free radicals, antioxidants in disease and health. Int J Biomed Sci 4: 89-96.

43 Kosower NS, Kosower EM (1978) The glutathione status of cells. Int Rev Cytol 54: 109-160.

44 Lushchak VI (2012) Glutathione homeostasis and functions: potential targets for medical interventions. J Amino Acids 2012: 1-26.

45 Schumacker PT (2015) Reactive Oxygen species in cancer: A dance with the devil. Cancer cell 27: 156-157.

46 Todorova VK, Kaufmann Y, Hennings L, Klimberg VS (2010) Ora glutamine protects against acute doxorubicin-induced cardiotoxicity of tumor-bearing rats. J Nutr 140: 44-48.

47 Papasani VMR, Hanumantharayappa B, Annapurna A (2014) Cardioprotective effect of naringin against doxorubicin induced cardiomyopathy in rats. Indo American Journal of Pharmaceutical Research 4: 2593-2598.

48 Kwatra M, Kumar V, Jangra A, Mishra M, Ahmed S, et al. (2016) Ameliorative effect of naringin against doxorubicin-induced acute cardiac toxicity in rats. Pharm Biol 54: 637-647.

49 Schnekenburger M, Karius T, Diederich M (2014) Regulation of epigenetic traits of the glutathione -S-transferase P1 gene: from detoxification toward cancer prevention and diagnosis. Front Pharmacol 5: 170.

50 Laborde E (2010) Glutathione transferases as mediators of signalling pathways involved in cell proliferation and cell death. Cell Death Differ 17: 1373-1380.

51 Mcllwain CC, Townsend DM, Tew KD (2006) Glutathione S-transferase polymorphisms: cancer incidence and therapy. Oncogene 25: 1639-1648.

52 McBride MW, Brosnan MJ, Mathers J, McLellan LI, Miller WH, et al. (2005) Reduction of Gstm1 expression in the stroke-prone spontaneously hypertension rat contributes to increased oxidative stress. Hypertension 45: 786-792.

53 Fattman CL, Schaefer LM, Oury TD (2003) Extracellular superoxide dismutase in biology and medicine. Free Radic Biol Med 35: 236-256.
54 Miller AF (2012) Superoxide dismutases: Ancient enzymes and new insights. FEBS Letters 586: 585-595.

55 Carillon J, Rouanet JM, Cristol JP, Richard B (2013) Superoxide dismutase administration, a potential therapy against oxidative stress related diseases: Several routes of supplementation and proposal of an original mechanism of action. Pharm Res 30: 2718-2728.

56 Vasquez-Vivar J, Martasek P, Hogg N, Masters BS, Pritchard Jr KA, et al. (1997) Endothelial nitric oxide synthase-dependent superoxide generation from adriamycin. Biochemistry 36: 11293-11297.

57 Turgut NH, Kara H, Elagoz S, Deveci K, Gungor H, et al. (2016) The protective effect of naringin against bleomycin-induced pulmonary fibrosis in wistar rats. Pulm Med 2016.

58 Kodydková J, Vávrová L, Kocík M, Žák A (2014) Human catalase, its polymorphisms, regulation and changes of its activity in different diseases. Folia Biol (Praha) 60: 153-167.

59 Yin $\mathrm{H}, \mathrm{Xu} \mathrm{L}$, Porter NA (2011) Free radical lipid peroxidation: mechanisms and analysis. Chem Rev 111: 5944-5972.

60 Pieniążek A, Czepas J, Piasecka-Zelga J, Gwoździński K, Koceva-Chyła (2013) Oxidative stress induced in rat liver by anticancer drugs doxorubicin, paclitaxel and docetaxel. Adv Med Sci 58: 104-111.

61 Jagetia GC, Reddy TK (2004) Chemopreventive effect of naringin on the benzo (a) pyrene-induced forestomach carcinoma in mice. Int J of Cancer Prevent 6: 429-444.

62 Guo RM, Xu WM, Lin JC, Mo LQ, Hua XX, et al. (2013) Activation of the p38 MAPK/NF-KB pathway contributes to doxorubicin-induced inflammation and cytotoxicity in $\mathrm{H} 9 \mathrm{c} 2$ cardiac cells. Mol Med Rep 8: 603-608.

63 Li D, Li J, An Y, Yang Y, Zhang SQ (2013) Doxorubicin-induced apoptosis in $\mathrm{H} 9 \mathrm{c} 2$ cardiomyocytes by NF-KB dependent PUMA upregulation. Eur Rev Med Pharmacol Sci 17: 2323-2329.

64 Jing L, Changyuan W, Jinyong P, Wenshuang L, Yue J, et al. (2016) Naringin regulates cholesterol homeostasis and inhibits inflammation via modulating NF-KB and ERK signaling pathways in vitro. Pharmazie 71: 101-108.

65 Kansanen E, Kuosmanen SM, Leinonen H, Levonen AL (2013) The Keap1-Nrf2 pathway: Mechanisms of activation and dysregulation in cancer. Redox Biology 1: 45-49.

66 Chen F, Zhang N, Ma X, Huang T, Shao Y, et al. (2015) Naringin alleviates diabetic kidney disease through inhibiting oxidative stress and inflammatory reaction. PLOS ONE 10: e0143868. 